\title{
Outsmarting the Liars: Toward a Cognitive Lie Detection Approach
}

\author{
Aldert Vrij', Pär Anders Granhag², Samantha Mann', and \\ Sharon Leal' \\ ${ }^{1}$ University of Portsmouth and ${ }^{2}$ University of Gothenburg
}

\begin{abstract}
Five decades of lie-detection research have shown that people's ability to detect deception by observing behavior and listening to speech is limited. The problem is that cues to deception are typically faint and unreliable. The aim for interviewers therefore is to ask questions that actively elicit and amplify verbal and nonverbal cues to deceit. We present an innovative lie-detection perspective based on cognitive load, demonstrating that it is possible to ask questions that raise cognitive load more in liars than in truth tellers. This cognitive lie-detection perspective consists of two approaches. The imposing-cognitive-load approach aims to make the interview setting more difficult for interviewees. We argue that this affects liars more than truth tellers, resulting in more and more-blatant cues to deceit. The strategic-questioning approach examines different ways of questioning that elicit the most differential responses between truth tellers and liars.
\end{abstract}

\section{Keywords}

interviewing to detect deception, imposing cognitive load, strategic-questioning approach

Five decades of lie-detection research have shown that people's ability to detect deception by observing behavior and listening to speech is limited - with, on average, $54 \%$ of truths and lies being correctly classified (Bond \& DePaulo, 2006). To improve accuracy rates, researchers have attempted to unravel the strategies used by certain individuals identified as having extraordinary lie-detection skills, so-called wizards (O'Sullivan \& Ekman, 2004). Is it the case that less sophisticated lie catchers can learn from these wizards? Some scholars doubt whether these identified individuals are real wizards (Bond \& Uysal, 2007), and, to date, no publication has emerged about the strategies these alleged wizards use (Bond, 2009). Other researchers have taught investigators "diagnostic" cues to deceit. The success of such training programs has been limited, with only a few percentage points, on average, gained in accuracy (Frank \& Feeley, 2003).

The problem is that cues to deception are typically faint and unreliable (DePaulo et al., 2003). One reason is that the underlying theoretical explanations for why such cues occurnervousness and cognitive load - also apply to truth tellers. That is, both liars and truth tellers can be afraid of being disbelieved and may have to think hard when providing a statement. Can interviewers ask questions that actively elicit and amplify verbal and nonverbal cues to deceit? Efforts in the past (e.g., Reid's Behavior Analysis Interview) have concentrated on
Science

$000(00)$ I-5

(C) The Author(s) 2010

Reprints and permission: sagepub.com/journalsPermissions.nav DOI: $10.1177 / 0963721410391245$ http://cdps.sagepub.com

(SAGE eliciting and amplifying emotions (Vrij, 2008), but it is doubtful whether questions that will necessarily raise more concern in liars than in truth tellers can be asked (National Research Council, 2003).

We will demonstrate, however, that it is possible to ask questions that raise cognitive load more in liars than in truth tellers. This cognitive lie-detection perspective consists of two approaches. The imposing-cognitive-load approach aims to make the interview setting more difficult for interviewees. We argue that this affects liars more than truth tellers, resulting in more and more-blatant cues to deceit. The strategicquestioning approach examines different ways of questioning that elicit the most differential responses between truth tellers and liars.

\section{The Imposing-Cognitive-Load Approach}

Lying can be more cognitively demanding than truth telling (Vrij et al., 2008). First, formulating the lie may be cognitively demanding. A liar needs to invent a story and must monitor

\section{Corresponding Author:}

Aldert Vrij, University of Portsmouth, Psychology Department, King Henry Building, King Henry I Street, Portsmouth, POI 2DY, United Kingdom

E-mail: aldert.vrij@port.ac.uk 
their fabrication so that it is plausible and adheres to everything the observer or observers know or might find out. Moreover, liars must remember what they have said to whom in order to maintain consistency. Liars should also refrain from providing new leads. Second, liars are typically less likely than truth tellers to take their credibility for granted. As such, liars will be more inclined than truth tellers to monitor and control their demeanor in order to appear honest to the investigator, and such monitoring and controlling is cognitively demanding. Third, because liars do not take credibility for granted, they may also monitor the investigator's reactions carefully in order to assess whether they appear to be getting away with their lie, and this too requires cognitive resources. Fourth, liars may be preoccupied with the task of reminding themselves to roleplay, which requires extra cognitive effort. Fifth, liars also have to suppress the truth while they are fabricating, and this is also cognitively demanding. Finally, while activation of the truth often happens automatically, activation of the lie is more intentional and deliberate, and thus requires mental effort.

A lie catcher could exploit the different levels of cognitive load that truth tellers and liars experience in order to discriminate more effectively between them. Liars who require more cognitive resources than truth tellers will have fewer cognitive resources left over. If cognitive demand is further raised, which could be achieved by making additional requests, liars may not be as good as truth tellers in coping with these additional requests.

One way to impose cognitive load is by asking interviewees to tell their stories in reverse order. This increases cognitive load because (a) it runs counter to the natural forward-order coding of sequentially occurring events, and (b) it disrupts reconstructing events from a schema (Gilbert \& Fisher, 2006). Another way to increase cognitive load is by instructing interviewees to maintain eye contact with the interviewer. When people have to concentrate on telling their storieslikely when they are asked to recall what has happened - they are inclined to look away from their conversation partner (typically to a motionless point), because maintaining eye contact is distracting (Doherty-Sneddon \& Phelps, 2005). In two experiments, half of the liars and truth tellers were requested to recall their stories in reverse order (Vrij et al., 2008) or to maintain eye contact with the interviewer (Vrij, Mann, Leal, \& Fisher, 2010), whereas no instruction was given to the other half of the participants. More cues to deceit emerged in the reverseorder and maintaining-eye-contact conditions than in the control conditions. Observers who watched these videotaped interviews could distinguish between truths and lies better in the reverse-order condition and maintaining-eye-contact conditions than in the control conditions. For example, in the reverse-order experiment, $42 \%$ of the lies were correctly classified in the control condition, well below that typically found in verbal and nonverbal lie-detection research, suggesting that the lie-detection task was difficult. Yet, in the experimental condition, $60 \%$ of the lies were correctly classified, more than typically found in this type of lie detection research.

\section{Strategic-Questioning Approach Unanticipated questions}

A consistent finding in deception research is that liars prepare themselves when anticipating an interview (Hartwig, Granhag, \& Strömwall, 2007). Planning makes lying easier, and planned lies typically contain fewer cues to deceit than do spontaneous lies (DePaulo et al., 2003). However, the positive effects of planning will only emerge if liars correctly anticipate which questions will be asked. Investigators can exploit this limitation by asking questions that liars do not anticipate. Though liars can refuse to answer unanticipated questions, such "I don't know" or "I can't remember" responses will create suspicion if the questions are about central (but unanticipated) aspects of the target event.

To test the unanticipated-questions technique, pairs of liars and truth tellers were interviewed individually about having had lunch together at a restaurant (Vrij et al., 2009). While the truth tellers did have lunch together, the liars did not but were instructed to pretend that they had. All pairs were given the opportunity to prepare for the interview. The interviewer asked conventional opening questions (e.g., "What did you do in the restaurant?"), followed by questions about spatial details (e.g., "In relation to where you sat, where were the closest diners?") and temporal details (e.g., "Who finished their food first, you or your friend?"). Further, they were asked to sketch the layout of the restaurant. The spatial questions and drawing requests came as a surprise to interviewees (this was established after the interview). Based on the overlap in responses between the two pair members to the anticipated questions, the liars and truth tellers were not classified above chance level. However, based on the responses to the unanticipated questions, up to $80 \%$ of pairs of liars and truth tellers were correctly classified (i.e., the answers to spatial questions and the answers to drawings were less alike for the pairs of liars than pairs of truth tellers). Asking unanticipated questions about central topics therefore elicited cues to deceit.

Asking unanticipated questions can also be effective when assessing individual interviewees rather than pairs of interviewees. An interviewer could ask the same question twice. When liars have not anticipated the question, they have to fabricate an answer on the spot. A liar's memory of this fabricated answer may be more unstable than a truth teller's memory of the actual event. Therefore, liars may contradict themselves more than do truth tellers. This approach probably works best if the questions are asked in different formats. Truth tellers will have encoded the topic of investigation along more dimensions than liars will have. Truth tellers should therefore be able to recall the event more flexibly (along more dimensions) than liars. When asked to verbally describe and sketch the layout of a restaurant, truth tellers' verbal answers and drawings showed more overlap than liars' verbal answers and drawings (Leins, Fisher, Vrij, Leal, \& Mann, in press).

Drawings have never been used before as a lie-detection tool, but they have potential, as demonstrated in two further experiments. More so than a verbal request, the request to 
sketch forces the interviewee to convey spatial information. That is, including an object within a drawing requires that object to be spatially located. By comparison, verbally describing an object in a room can be done without indicating its spatial location. If a liar has not experienced an item in a particular location, he or she may still verbally describe the object but will do so without referring to its location to avoid the risk of misplacing it. Such a "masking strategy" is not possible when asked to sketch. As a result, a liar may instead decide against sketching the object. In an occupations experiment, truth tellers discussed their real occupations, whereas liars discussed occupations they pretended to have. When asked to verbally describe the layout of their office, truth tellers' and liars' answers were equally detailed; however, when asked to sketch the layout of their offices, liars' drawings were less detailed than were those of truth tellers (Vrij, Mann, Leal, \& Fisher, in press).

In a second experiment, 31 "agents" were sent on a mission during which they had to collect a decoder from another agent (Vrij et al., 2010). After delivering the decoder, they were asked to (a) verbally describe and later to (b) sketch what they could see at the location where they had received the decoder. Half of the agents were requested to lie and half to tell the truth. The liars were asked to pretend to have been on a different mission in which they received the decoder at a different location. Only 2 out of $16(12.5 \%)$ liars included an agent from whom they pretended to have received the decoder in their drawing, whereas 12 out of 15 truth tellers $(80 \%)$ included the real agent in their drawing. In their verbal descriptions, again 2 out of $16(12.5 \%)$ liars mentioned the other agent, whereas 8 out of $15(53 \%)$ truth tellers did so. In other words, like the occupations experiment, truth tellers' and liars' drawings differed more from each other than did truth tellers' and liars' verbal recalls. Liars were inclined to omit the agent from the sketch and verbal description for two possible reasons: First, the agent had not been present at the location they sketched/described, and therefore did not think about including him/her. Second, liars may have been reluctant to include people in their drawings/descriptions for fear of triggering further questions about who those people actually were. Note that more truth tellers sketched (80\%) than verbally described the agent (53\%), demonstrating why drawings were more informative about deception than verbal recalls. After sketching the stable elements, the truth tellers probably noticed that the agent was missing from the drawing. Liars, however, will have been less aware of this during their verbal recall, because of difficulties in building a complete mental picture of their verbal recall.

\section{Devil's-advocate approach}

Spatial and drawing requests are unsuitable when examining lying about opinions. Determining the veracity of such conceptual representations can be important in security settings, as demonstrated by the loss of seven CIA agents in Afghanistan. They were killed via a suicide attack by a man they believed was going to give them information about Taliban and
al-Qaeda targets in Pakistan's tribal areas. The CIA was aware that he had posted extreme anti-American views on the internet but believed these to be part of a cover (Leal, Vrij, Mann, \& Fisher, in press).

The devil's-advocate technique aims to detect deception in expressing opinions. Interviewees are first asked an opinioneliciting question that invites them to argue in favor of their personal view ("What are your reasons for supporting the U.S. in the war in Afghanistan?"). This is followed by a devil's-advocate question that asks interviewees to argue against their personal view ("Playing devil's advocate, is there anything you can say against the involvement of the U.S. in Afghanistan?").

People normally think more deeply about, and are more able to generate, reasons that support rather than oppose their beliefs (Ajzen, 2001). Therefore, truth tellers are likely to provide more information in their responses to the true opinioneliciting question than to the devil's-advocate question. This pattern is unlikely to occur in liars, as for them, the devil'sadvocate question is more compatible with their beliefs than is the opinion-eliciting question. In effect, for liars, the devil'sadvocate approach is a set-up wherein they first lie when answering the opinion-eliciting question and then are lured into telling the truth when answering the devil's-advocate question. In an experiment, participants were asked to tell the truth or lie about their views regarding issues they felt strongly about, including the war in Afghanistan. Truth tellers' opinioneliciting answers were longer than their devil's-advocate answers, whereas no differences emerged in liars' answers to the two types of question (Leal et al., in press). Based on this principle, $75 \%$ of truth tellers and $78 \%$ of liars could be classified correctly.

\section{The strategic use of evidence (SUE)}

Lying and truth-telling suspects enter police interviews in different mental states (Granhag \& Hartwig, 2008). A guilty suspect will often have unique knowledge about the crime, which, if recognised by the interviewer, makes it obvious that he or she is the perpetrator. The guilty suspect's main concern will be to ensure that the interviewer does not gain that knowledge. Innocent suspects face the opposite problem, fearing that the interviewer will not learn or believe what they did at the time of the crime. These different mental states result in different strategies for liars and truth tellers (Hartwig et al., 2007). Guilty suspects are inclined to use avoidance strategies (e.g., in free recall, avoiding mentioning where they were at a certain time) or denial strategies (e.g., denying having been at a certain place at a certain time when directly asked). In contrast, innocent suspects neither avoid nor escape but are forthcoming and "tell the truth like it happened" (Granhag \& Hartwig, 2008).

In the SUE technique, the investigator aims to detect these differential strategies via a strategic use of the available evidence (e.g., possible incriminating information). The purpose of SUE is to ask open questions (e.g., "What did you do last Sunday afternoon?") followed by specific questions (e.g., "Did 
Vrij et al.

you or anyone else drive your car last Sunday afternoon?") without revealing that evidence (e.g., closed-circuit TV images of the interviewee's car driven in a specific location on that Sunday afternoon). Truth tellers are likely to mention driving the car on that Sunday afternoon either spontaneously or after being prompted (e.g., "tell the truth like it happened" strategy). Liars are unlikely to mention driving the car spontaneously (e.g., avoidance) or after being prompted (e.g., denial). A denial will contradict the evidence.

Hartwig, Granhag, Strömwall, and Kronkvist (2006) experimentally tested the SUE technique. Prior to the experiment, half of the interviewers were SUE trained and were instructed to interview the suspect using the SUE technique. The remaining interviewers were instructed to interview the suspect in the style of their own choice. The untrained interviewers obtained $56.1 \%$ accuracy (similar to that typically found in nonverbal and verbal lie detection research), whereas the SUE-trained interviewers obtained $85.4 \%$ accuracy. Guilty suspects contradicted the evidence more often than did innocent suspects, particularly when questioned by SUE-trained interviewers.

\section{Final Thoughts}

The lie-detection techniques that we have discussed can be employed in various settings. SUE can be used when evidence is available, and the devil's-advocate technique can be employed when examining the veracity of opinions. The other techniques can be employed to determine the veracity of statements about past activities but, in theory, also to determine the veracity of statements about future activities (intentions). We have shown that the unanticipated questions technique can be employed to identify deceit in both individuals and networks (multiple liars). Future research should examine whether the techniques are sensitive to countermeasures - that is, liars' attempts to fool investigators. The unanticipated-question technique should be immune to this, as its method is to ask questions that a liar has not anticipated and therefore not prepared answers for. Due to individual differences in people's responses, within-subjects lie-detection techniques are preferred because they control for such individual differences. The unanticipated-questions and devil's-advocate techniques are within-subjects techniques.

\section{Recommended Reading}

DePaulo, B.M., Lindsay, J.L., Malone, B.E., Muhlenbruck, L., Charlton, K., \& Cooper, H. (2003). (See References). A meta-analysis of verbal and non-verbal cues to deceit.

Granhag, P.A. \& Hartwig, M. (2008). (See References). An empirical and theoretical overview of the strategic-use-of-evidence (SUE) technique.

Kassin, S.M. (2005). On the psychology of confessions: Does innocence put innocents at risk? American Psychologist, 60, 215-228. A discussion of the consequences of incorrect veracity judgements in police interviews.

Vrij, A. (2008). (See References). A thorough and comprehensive review of cues to deception and lie detection methods.

\section{Declaration of Conflicting Interests}

The authors declared that they had no conflicts of interest with respect to their authorship or the publication of this article.

\section{References}

Ajzen, I. (2001). Nature and operation of attitudes. Annual Review of Psychology, 52, 27-58.

Bond, C.F., \& DePaulo, B.M. (2006). Accuracy of deception judgements. Personality and Social Psychology Review, 10, 214-234.

Bond, C.F., \& Uysal, A. (2007). On lie detection "wizards." Law and Human Behavior, 31, 109-115.

Bond, G.D. (2009). Deception detection expertise. Law and Human Behavior, 32, 339-351.

DePaulo, B.M., Lindsay, J.L., Malone, B.E., Muhlenbruck, L., Charlton, K., \& Cooper, H. (2003). Cues to deception. Psychological Bulletin, 129, 74-118.

Doherty-Sneddon, G., \& Phelps, F.G. (2005). Gaze aversion: A response to cognitive or social difficulty? Memory and Cognition, 33, 727-733.

Frank, M.G., \& Feeley, T.H. (2003). To catch a liar: Challenges for research in lie detection training. Journal of Applied Communication Research, 31, 58-75.

Gilbert, J.A.E., \& Fisher, R.P. (2006). The effects of varied retrieval cues on reminiscence in eyewitness memory. Applied Cognitive Psychology, 20, 723-739.

Granhag, P.A. \& Hartwig, M. (2008). A new theoretical perspective on deception detection: On the psychology of instrumental mindreading. Psychology, Crime \& Law, 14, 189-200.

Hartwig, M., Granhag, P.A., Strömwall, L., \& Kronkvist, O. (2006). Strategic use of evidence during police interrogations: When training to detect deception works. Law and Human Behavior, 30, 603-619.

Hartwig, M., Granhag, P.A., \& Strömwall, L. (2007). Guilty and innocent suspects' strategies during interrogations. Psychology, Crime, \& Law, 13, 213-227.

Leal, S., Vrij, A., Mann, S., \& Fisher, R. (in press). Detecting true and false opinions: The devil's Advocate approach as a lie detection aid. Acta Psychologica.

Leins, D., Fisher, R.P., Vrij, A., Leal, S., \& Mann, S. (in press). Using sketch-drawing to induce inconsistency in liars. Legal and Criminological Psychology.

National Research Council, Committee to Review the Scientific Evidence on the Polygraph. (2003). The polygraph and lie detection. Washington, DC: The National Academies Press.

O'Sullivan, M., \& Ekman, P. (2004). The wizards of deception detection. In P.A. Granhag \& L.A. Strömwall (Eds.), Deception detection in forensic contexts. (pp. 269-286). Cambridge, England: Cambridge University Press.

Vrij, A. (2008). Detecting lies and deceit: Pitfalls and opportunities, second edition. Chichester, England: John Wiley and Sons.

Vrij, A., Leal, S., Granhag, P.A., Mann, S., Fisher, R.P., Hillman, J., \& Sperry, K. (2009). Outsmarting the liars: The benefit of asking unanticipated questions. Law and Human Behavior, 33, 159-166. 
Vrij, A., Leal, S., Mann, S., Warmelink, L., Granhag, P.A., \& Fisher, R.P. (2010). Drawings as an innovative and successful lie detection tool. Applied Cognitive Psychology, 4, 587-594.

Vrij, A., Mann, S., Fisher, R., Leal, S., Milne, B., \& Bull, R. (2008). Increasing cognitive load to facilitate lie detection: The benefit of recalling an event in reverse order. Law and Human Behavior, 32, 253-265.
Vrij, A., Mann, S., Leal, S., \& Fisher, R. (2010). "Look Into My Eyes": Can an instruction to maintain eye contact facilitate lie detection? Psychology, Crime, \& Law, 16, 327-348.

Vrij, A., Mann, S., Leal, S., \& Fisher, R. (in press). Is anyone out there? Drawings as a tool to detect deception in occupations interviews. Psychology, Crime, \& Law. 